See Article page 170.

\section{Commentary: Almost ready for prime time}

\author{
Lawrence M. Wei, MD
}

In this issue of JTCVS Techniques, Torregrossa, Amabile, and Balkhy ${ }^{1}$ of the University of Chicago have elegantly demonstrated their technique of totally endoscopic coronary artery bypass (TECAB) with robotically sutured anastomoses. Balkhy and colleagues ${ }^{2}$ have been pioneers in robotic coronary revascularization and have performed multivessel TECAB procedures using off-pump techniques, facilitated by a robotic coronary stabilizer and a mechanical anastomotic stapler. Because the anastomotic device is no longer produced, they developed and have reported in this issue their method of sewing coronary anastomoses robotically.

Since Loulmet and colleagues ${ }^{3}$ performed the first robotic coronary artery bypass operations on arrested hearts in 1999 , the ability to perform multivessel, off-pump robotic coronary artery bypass grafting (CABG) has been an elusive goal. Most surgeons who have used robotic assistance for coronary revascularization have harvested the mammary conduits robotically and manually sewn the distal anastomoses, off pump, through a small thoracotomy. This approach has proved to be highly successful, with angiographic results reportedly equivalent to those of CABG via sternotomy but has been limited in the accessibility of distal targets other than the left anterior descending and diagonal arteries. ${ }^{4}$ Balkhy's team is among a very small number of surgeons who have performed the operation endoscopically, and they have extended the technique to

\footnotetext{
From the Department of Cardiovascular and Thoracic Surgery, Heart and Vascular Institute, West Virginia University, Morgantown, WVa.

Disclosures: The author reported no conflicts of interest.

The Journal policy requires editors and reviewers to disclose conflicts of interest and to decline handling or reviewing manuscripts for which they may have a conflict of interest. The editors and reviewers of this article have no conflicts of interest.

Received for publication June 17, 2020; revisions received June 17, 2020; accepted for publication June 17, 2020; available ahead of print June 24, 2020.

Address for reprints: Lawrence M. Wei, MD, Department of Cardiovascular and Thoracic Surgery, Heart and Vascular Institute, West Virginia University, PO Box 8003, One Medical Center Drive, Morgantown, WV 26506 (E-mail: lawrence.wei@wvumedicine.org).

JTCVS Techniques 2020;3:174-5

2666-2507

Copyright (c) 2020 The Authors. Published by Elsevier Inc. on behalf of The American Association for Thoracic Surgery. This is an open access article under the CC BY-NCND license (http://creativecommons.org/licenses/by-nc-nd/4.0/).

https://doi.org/10.1016/j.xjtc.2020.06.029
}

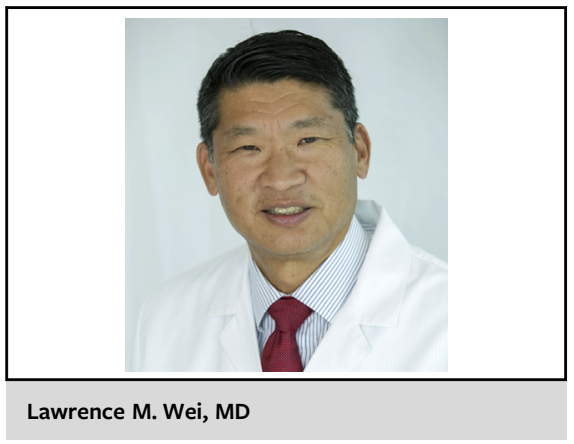

CENTRAL MESSAGE

A dedicated, experienced team demonstrates how to perform robotically sutured coronary artery anastomoses, a technique that will be useful for a select group of surgeons.

performing multivessel robotic TECAB, off pump, with bilateral mammary arterial grafts. ${ }^{2}$

It has been more than 2 decades since the initial report of Loulmet and colleagues. ${ }^{3}$ However, among the millions of $\mathrm{CABG}$ operations since performed, very few have been robotic TECAB procedures, and only a fraction of these were off pump. The reported series of robotic TECAB have all been single-arm studies of selected patients and have not included long-term follow-up data. Many surgeons, even those with substantial robotic experience, have chosen not to pursue robotic TECAB. Others have attempted and then abandoned the approach. The technical difficulty in performing robotic coronary anastomoses spurred the development of mechanical devices to facilitate their construction; however, the device shortcomings and limited demand has led to their demise and the need to develop the intricate technique illustrated in their report. The authors' considerable ingenuity and perseverance will once again be tested in the near future because the small number of robotic TECAB operations being performed has led Intuitive Surgical, Inc (Mountain View, Calif) to discontinue manufacture of the robotic stabilizer used in the study by Torregrossa and colleagues. ${ }^{1}$

Balkhy and colleagues ${ }^{1,2}$ are to be applauded for their efforts to develop the techniques of robotic coronary revascularization and for their persistence in achieving successful outcomes. However, the technical challenges and limited reproducibility of robotic TECAB has meant that, for the 
vast majority of surgeons, this operation will likely always remain in the holding pattern of being almost ready for prime time.

\section{References}

1. Torregrossa G, Amabile A, Balkhy HH. Totally robotic sutured coronary artery bypass grafting: how I do it. J Thorac Cardiovasc Surg Tech. 2020;3:170-2.
2. Balkhy HH, Nisivaco S, Kitahara H, McCrorey M, Patel B. Robotic multivesse endoscopic coronary bypass: impact of a beating-heart approach with connectors. Ann Thorac Surg. 2019;108:67-73.

3. Loulmet D, Carpentier A, d'Attellis N, Berrebi A, Cardon C, Ponzio O, et al Endoscopic coronary artery bypass grafting with the aid of robotic assisted instruments. J Thorac Cardiovasc Surg. 1999;118:4-10.

4. Halkos ME, Liberman HA, Devireddy C, Walker P, Finn AV, Jaber W, et al. Early clinical and angiographic outcomes after robotic-assisted coronary artery bypass surgery. J Thorac Cardiovasc Surg. 2014;147:179-85. 